\title{
Relações éticas na Atenção Básica em Saúde: a vivência dos estudantes de medicina
}

\author{
Ethical relationship in Primary Health Care: \\ the experience of medical students
}

Ricardo Corrêa Ferreira ${ }^{1}$

Roseli FerreiradaSilva ${ }^{2}$

M aurício Braz Zanolli ${ }^{1}$

Cássia Regina Rodrigues Varga ${ }^{2}$

${ }^{1}$ Faculdadede M edicina de Marília. Av. M onte Carmelo 800, Fragata. 17519-030 Marília SP. riguaira@famema.br

${ }^{2}$ Centro de Ciências Biológicas eda Saúde,

Departamento deM edicina, UniversidadeFederal de São Carlos.
Abstract The ethical formation of doctors involves professional relationships that are part of their daily routine, and in this context, Faculdade de M edicina de M arília (Famema) provides the medical students to live deeply since the beginning of the course at the Education Unit of Professional Practice, the ethical reflection of the actions in health when developing abilities in the Primary $\mathrm{H}$ ealth $\mathrm{Care}(\mathrm{PHC})$ together with the community. This scientific research analyzed the perception of academics of medicine on the first and second years concerning ethical actions in health developed together with the community. The qualitative approach was the option of analysis of this study that allowed the construction of three empirical categories common to the two years: The ethical and professional training in PHC's reality; Confidentiality of information on the development of medical professional secrecy; interpersonal relationships on ethical formation of medicine students, with more predominance of the second category among the first years students. Therefore, the ethical relations are more significant to the students when lived deeply, since the beginning in practices like these. Key words M edical ethics, M edical education, $\mathrm{Hu}$ man relations
Resumo A formação ética dos médicos envolve as relações profissionais que fazem parte de seu cotidiano e, neste sentido, a Faculdade deM edicina de M arília (Famema) propicia aos estudantes de medicina vivenciar desde o início do curso, na Unidade Educacional de Prática Profissional (UPP), a reflexão sobre a prática e sobre a ética das ações em saúde na Atenção Básica em Saúde (ABS) junto à comunidade. Analisou-se, nesta pesquisa, a percepção dos acadêmicos de medicina das $1^{\underline{a}}$ e $2^{\underline{a}}$ séries acerca das relações éticas en volvidas nas ações em saúde junto à comunidade. A abordagem qualitativa foi a opção de análise desta investigação que permitiu a construção de três categorias empíricas comuns às duas séries: A formação ética e profissional na realidade da ABS; Confidencialidade da informação no desenvolvimento do sigilo profissional médico; As relações interpessoais na formação ética do estudante de medicina, com maior predominância da segunda categoria entre os da 1a série. Portanto, as relações éticas são mais significativas aos estudantes quando vivenciadas, desde o início, em práticas como estas. Palavras-chave Ética médica, Educação médica, Relações humanas 
Introdução

A ética nas relações profissionais se faz através de responsabilidade, compromisso com o trabal ho e com o outro, assim como pelo respeito eafetividade às pessoas. Para tanto, a ética se desenvolve na formação profissional quando atitudes, valores e habilidades são construídos no exercício desta prática profissional ${ }^{1}$.

Neste contexto, a Unidade de Prática Profissional (UPP), parte do novo currículo da Famema a partir de 2003, propicia aos acadêmicos de medicina das 1 a e $2 \underline{a}$ séries o contato com a comunidade mariliensena medida em que os mesmos desenvolvem o cuidado em saúde a esta comunidade no contexto das Unidades de Saúde da Família (USF). Desde o início do curso, os acadêmicos desenvolvem capacidades (cognitivas, psicomotoras e afetivas) que os instrumentalizam na identificação das necessidades de saúde e na elaboração de proble mas edo plano de cuidados que envolvem a comunidade. Para tanto, interagem em relaçõesinterpessoais que devem ser pautadas nos princípios ecomportamentos éticos em suas ações de saúde.

Este estudo deverá contribuir para o desenvolvimento curricular dos cursos da área da saúde que almejem propiciar, aos acadêmicos, vivências e comportamentos éticos em diferentes cenários de apren dizagem .

O sistema desaúdeatual ea ética profissional

Inúmeras mudanças sociais, éticas, econômicas e políticas vêm sendo observadas em âmbito mundial, que, de forma incisiva, têm atingido os sistemas de saúde. Gerou-se, então, um enorme desafio na condução destes, tanto para os responsáveis envolvidos com o planejamento e a atenção em saúde, como para os órgãos formadores de recursos humanos para o setor da saúde².

0 acesso à saúde de qualidade não éum direito real da maioria dos brasileiros e este acesso não depende somente de uma transformação das condições de vida, mas também de mudanças no modelo de atenção à saúde a fim de se assumir uma concepção ampla da mesma, cerceada de preceitos éticos e morais que transformem a qualidade dos serviços de saúde?.

Entre outros problemas na saúde, está a questão dos recursos humanos nesta área, sendo que há muitas críticas na formação de seus profissionais, algumas delas relacionadas às atitudes éticas ou às relações profissionais. Vive-seum esgotamento do modelo tradicional de sua formação e esta não está sendo adequada às necessidades atuais ${ }^{3}$.
Para tanto, são necessárias estratégias que sensibilizem e mobilizem todos que precisam se envolver na construção de mudanças, a fim de se atingir a reflexão crítica das relações em saúde.

$E$, neste contexto de mudanças, é inerente formar profissionais com perfil social eético capaz de aprender a aprender, trabalhar em equipe, comunicar-se, relacionar-se com o outro e ter percepções ágeis de ações 4 .

Assim, os órgãos formadores têm uma enorme responsabilidade na profissionalização, para que esta seja condizente com soluções aos novos paradigmas sociais, éticos e econômicos que surgem no processo de construção do sistema de saúde $^{5}$. Necessita-se, então, de uma formação diferenciada da que ocorre atualmente.

\section{A formação dos profissionais médicos}

Entendemos que, dentro da formação médica, várias temáticas como eutanásia, aborto, esterilização humana, sigilo profissional, relação médico-paciente, ética profissional, relações interpessoais fazem parteda demanda da formação do profissional médico, sendo necessário refletir acerca desta formação.

0 crescente desenvolvimento detecnologias na saúde e sua incorporação no dia a dia dos médicos trazem a estes profissionais questionamentos sobre os quais não existem reflexões sedimentadas em sua formação, levando-os, muitas vezes, a tomarem decisões baseadas apenas em seu bom-senso. Esse fato advém da crise do paradigma da ética médica tradicional, que é essencialmente deontológica, ou seja, sustentada em deveres da não maleficência eda beneficência, quenão são capazes de solucionar muitos conflitos que se apresentam na atualidade, criando um período de conflito entrea deontologia e a bioética ${ }^{6-8}$.

A formação médica, pautada no paradigma da racionalidade técnica, que gera, reproduz ou mesmo inculca valores, tem sido amplamente criticada, já que tem seu caráter baseado no cientificismo eno pragmatismo, o que implica uma postura "fria", "objetiva" e "neutra" do médico ao atender um paciente, cultivando-se valores de individualismo e competição, em substituição a valores que deveriam gerar a melhor forma de viver em sociedade 9 .

A escola médica não tem cumprido seu papel de ser um espaço de discussão das dificuldades éticas vivenciadas pelos estudantes, não capacitando adequadamente estes para lidar com os desafios éticos e morais com os quais se depararão no dia a dia de sua prática profissional8,10.

Ainda, o estudante de medicina está inserido em escolas que tratam as questões éticas como 
aquisição de conhecimento baseado na transmissão de saberes, e não como atitudes e valores desenvolvidos academicamente a fim de se valorizar o fazer, construindo-se o conhecimento a partir da prática nas relações com o outro ${ }^{9}$. E, para isto, é necessária uma nova racionalidade.

Esta se tem constituído em um novo paradigma cultural, entendido como nova visão do mundo e caracterizado por uma racionalidade crítica e emancipatória dos sujeitos e das instituições que o orientam, em que se pretende uma nova forma de estar e viver a profissão, assumindo que, perante a constante mudança e exigência dos contextos de atuação, a formação ao longo da vida surja como um imperativo inquestionável ${ }^{9}$.

Para Siqueira ${ }^{11}$, a defesa da vida deve ser a preocupação do estudante de medicina, assim como as atividades na universidade deveriam ser pautadas na intransigente valorização da vida humana, em que qualquer intervenção que os estudantes viessem praticar fosse olhada criticamente e reflexivamente.

0 estudante deve evitar qualquer atitude que coloque em risco a vida e qualidade de vida do paciente, assim como deve apreender o contexto de vida deste. Espera-se do estudante uma compreensão real das necessidades de saúde dos indivíduos e saber ouvir com atenção o outro, ter calma e prudência em suas atitudes, ser tolerante e razoável com as manifestações do paciente ${ }^{11}$, jáque a sociedade não é mais a mesma, a ciência não responde a todas as questões e o saber científico não édomínio exclusivo da classe médica, além de que os pacientes mudaram e não são tão "pacientes" como em tempos passados.

Sendo, então, competência técnica, aprimoramento constante, respeito às pessoas, confidencialidade, privacidade, flexibilidade, fidelidade, envolvimento, afetividade, correção de conduta, boas maneiras, relações humanas, inter-relacionamento, relações de responsabilidadeimprescindíveis na construção de relações profissionais éticas e interpessoais dos estudantes ${ }^{12}$.

\section{O contexto das relações interpessoais}

Acerca das relações humanas, estas se dão cada vez mais no âmbito da razão instrumental, uma razão de domínio, despótica, tornando o homem insensível à realidade, que só conhece o que faz, deseja uma realidade de certezas e segurança, e que não deixa nada à "improvisação da natureza" ${ }^{13}$.

Para 0 autor, a plenitude da relação, entretanto, é alcançada quando se tem um caráter recíproco dos homens, em que se abrem âmbitos de cor- relação que potencializem as duas pessoas em uma relação que o homem manifesta-se em sua plenitude, com reciprocidade e mútua responsabilidade para com o outro, produzindo e manifestando o conhecimento do próprio ser, da própria condição pessoal, do crescimento de humanidade.

Contudo, com o desenvolvimento tecnológico na saúde, com a descoberta de medicamentos e 0 uso de aparelhagens modernas, surgiram novos val ores no campo das relações interpessoais. Afloraram-se novos conhecimentos científicos e colocaram-seem questão conflitos nunca antes gerados ${ }^{13}$.

Tornaram-se necessárias, assim, reflexões éticas sobre o impacto que os avanços tecnológicos propiciaram nas relações dos seres humanos. $\mathrm{E}$ sobre o comportamento ético que se estabeleceu nas relações interpessoais, visam-se reflexões acerca dos valores impressos nas relações humanas, repletas de valores e anti-valores que se chocam a partir de então ${ }^{13}$.

Desta forma a Famema pretende, em seu currículo inovador, proporcionar a seus estudantes de medicina, o desenvolvimento de suas relações interpessoais acopladas ao desenvolvimento de atitudes e reflexões éticas na sua formação.

\section{Uma proposta de formação inovadora}

Na Famema, a Unidade de Prática Profissional (UPP) passou, a partir de 2003, a contribuir para a formação diferenciada do profissional de saúde, estabelecendo, para tanto, desempenhos e atitudes de acordo com o profissional desaúde quea sociedade necessita.

N esta formação, o estudante é motivado a se comunicar claramente e a desenvolver capacidades para um adequado trabalho em equipe, de modo a satisfazer as necessidades de saúde de pacientes, famílias, da comunidade. Participa da exploração de problemas e situações, em que traz consigo capacidades prévias (conhecimento, valores, representações eexperiências), para a construção de objetivos de aprendizagem e sua formação ético-profissional. Busca, então, informações e faz a análise crítica, discussão, articulação, integração e aplicação destas em sua formação profissional. Dessa forma, surge o currículo inovador em que a aprendizagem é individualizada e tem como objetivo estimular o estudante a desenvolver a capacidade de aprender a aprender na realidade na qual se insere ${ }^{14}$.

Com isso, coloca-se em prática a pedagogia crítica, em que se incorpora a experiência do acadêmico ao currículo, eo entendimento eresolução das contradições sociais e éticas que se vive ${ }^{15}$. 
E, nesta perspectiva, a UPP objetiva no plano curricular da Famema enfrentar esses desafios da formação dos profissionais de saúde, utilizandose, para tanto, cenários de prática - aprendizagem diversificada e condizente com as situações reais vivenciadas pela comunidade mariliense, utilizando-se, para tanto, a situação serviço - Unidade de Saúde da Família (USF) ${ }^{16}$.

Portanto, a UPP propicia, na formação dos estudantes de medicina já na primeira série da Famema, a instrumentação necessária para a integralidade de sua aprendizagem.

N esta unidade educacional, há interdisciplinaridade quando estes trabalham juntos e com uma equipe de USF - estudantes de enfermagem, agentes comunitários, médico eenfermeiro do serviço e ou docentes médicos e enfermeiros, dentista, assistentesocial, psicóloga, auxiliares deenfermagem - na resolução de problemas enecessidades desaúde da comunidade abrangente da área da USF. Elaboram planos de ação conjuntos, o que propicia pesquisa-ação e diálogo de saberes com os diversos sujeitos - tutores, consultores, profissionais de saúde, colegas -, vivenciam situações reais dos princípios éticos e morais, abordam diferenças históricas, culturais e sociais na construção da integralidade da atenção à saúde.

\section{Objetivo}

A nalisar a percepção dos estudantes das $1^{\underline{a}}$ e $2^{\underline{a}}$ séries de medicina da Famema acerca das relações éticas que estão envolvidas no cuidado à saúde junto à comunidade, no contexto da Unidade Educacional dePrática Profissional (UPP) do curso demedicina.

\section{M étodo}

Esta investigação se desenvolveu através de um estudo qualitativo sobre as relações éticas dos estudantes de medicina das $1 \underline{\text { a }}$ e $2^{\underline{a}}$ séries da Famema em relação às atividades desenvolvidas na UPP. Acredita-se que a análise de atitudes, motivações, expectativas e valores destes estudantes frente a UPP é mais bem compreendida através de uma abordagem qualitativa ${ }^{17}$. Este tipo de estudo também compreende e classifica processos dinâmicos vividos por grupos sociais e contribui para o processo de mudança e entendimento do comportamento dos indivíduos, envolveinteressemaior pelo cotidiano do que por fatos isolados, além de se ter maior utilização de significados em detrimento da frequência de fatos. Desta forma, dá-se ênfase ao desenvolvimento da percepção dos estudantes ${ }^{18}$.

\section{População e sujeitos}

0 universo desta investigação conta com 160 estudantes. Para a coleta de dados, foram incluídos vinte estudantes escol hidos de forma al eatória e representativa, mediante seleção por sorteio de um estudante de medicina de cada um dos vinte grupos da UPP das $1^{\text {a }}$ e $2^{\text {a }}$ séries. Os sujeitos, os vinte estudantes, foram separados por série para a coleta de dados.

\section{Aspectos éticos e procedimentos de coleta}

Esta pesquisa, atendendo aos procedimentos previstos na Resolução 196/96 do Conselho Nacional de Saúde, foi aprovada pelo Comitê de Ética em pesquisa da instituição em que foi desenvolvida, acrescentando-se, ainda, que não houve conflitos de interesse dos autores na pesquisa.

Para coleta dos dados, foi utilizada a técnica de grupo focal, que consiste numa entrevista em grupo, baseada em um tópico a ser explorado. Esta investigação utilizou-se de dois grupos focais, um grupo composto por dez estudantes da $11^{\mathrm{a}}$ série de medicina, outro grupo por dez estudantes da $2^{2}$ série. A pós a concordância na partici pação, os acadêmicos assinaram o termo de consentimento livre e esclarecido. Para tanto, fizeram-se perguntas norteadoras da discussão, as quais envolveram a percepção dos estudantes nas atividades e ações em saúde com a comunidade mariliense na UPP, que foram as seguintes: a) Como são as relações quevocês desenvolvem no cuidado à saúde junto à comunidade? b) Como se desenvolvem as relações éticas neste cuidado? c) Vocês observaram algum problema ético nestas relações?

\section{Forma de análise dos resultados}

Para a análise dos dados, foi utilizada a técnica de análise de conteúdo, a qual, segundo Bardin ${ }^{19}$, é "uma técnica de investigação que através de uma descrição objetiva, sistemática e quantitativa do conteúdo manifesto das comunicações, tem por finalidade a interpretação destas mesmas comunicações". Foi real izada uma leitura das transcrições das fal as dos participantes dos grupos focais, desmembradas em unidades de registro, ou seja, foi feita uma codificação, que corresponde a uma transformação dos dados brutos do texto para que se conseguisse atingir uma representação do conteúdo visando à categorização. Cada estudante foi representado por $E$ (E1, E2 ... E10) e separado em M 1 ( 1 a série deM edicina) eM 2 (2ª série de M edicina). 


\section{Discussão dos resultados}

A análise dos dados permitiu a construção de três categorias empíricas comuns às duas séries: A formação ética e profissional na realidade da Atenção Básica em Saúde (ABS); Confidencialidade da informação no desenvolvimento do sigilo profissional médico; As relações interpessoais na formação ética do estudante de medicina, com predominância da categoria confidencialidade entre os estudantes de medicina da 1 à série.

As categorias empíricas construídas neste estudo permitem compreender a capacidade transformadora que a UPP propicia aos estudantes de medicina da Famema, na medida em que os mesmos atuam num contexto real da prática profissional, como é a da ABS, e se relacionam com as pessoas da comunidade, construindo uma formação profissional ética e reflexiva. Cada uma das categorias será abordada a seguir.

\section{A formação ética e profissional na realidade da Atenção Básica em Saúde}

N esta categoria, os estudantes de ambas as séries do curso de medicina demonstram a importância que o cuidado à saúde da comunidade, na ABS, traz para uma construção de postura profissional diferenciada, notadamente na formação de profissionais que saibam respeitar a cultura das pessoas, seus costumes e valores, e que se empenhem na melhora na qualidade de vida da comunidade, estabelecendo, para tanto, vínculos de forma ética e respeitosa.

Elliot Turie ${ }^{20}$, que propõe a teoria dos domínios de conhecimento social, construídos como estruturas sociocognitivas queseorganizam, destaca-senesta categoria ao elucidar a importância dos seres humanos organizarem e desenvolverem seus conhecimentos a partir de suas interações sociais com a comunidade. Estaimportânciaéexpressa em uma perspectiva construtivista complexa enão-linear, na qual os estudantes constroem o conhecimento moral e social através do envolvimento com o ambiente e a cultura de seus pacientes, sem é claro desconsiderarem suas prerrogativas pessoais de moral ${ }^{20,21}$.

É um desafio lidar com essas questões, como a cultura e a vida das pessoas, suas vivências. Temos quetentar melhorar a qualidade devida das pessoas, esse que é o desafio. (E2M 1)

O s pacientes da minha área el es são bastante carentes. Se preocupam se não vamos lá, gostam da preocupação que temos com a saúde deles. (E2M 2)

Destaca-senestemomento um processo de sintonia com a teoria piagetiana, de sólida base cognitivista e interacionista, em que se amplia a dis- cussão do desenvolvimento moral no ensino da ética na formação médica, agora não mais como conteúdo a ser "depositado" no conhecimento estudantil, mas como uma formação ética e profissional construída cognitivamente através de interações com os pacientes em suas distintas dimensões, que oportunizam a aquisição de novos referenciais e conceitos ${ }^{21,22}$. Há, então, um equilíbrio progressivo, no qual o estudante, ao lidar com as diversas situações, tenta compreendê-las, dentro de uma passagem constante do estado de equilíbrio para o de desequilíbrio, mas que resulta num equilíbrio superior eque contribui paraa eficiência de uma ação no ambiente social22.

Para Piaget, o contexto social constrói o conhecimento e o juízo moral, eestar junto às pessoas interagindo com as mesmas exige organização cognitiva de si e do mundo, movendo o sujeito em sua evolução, e nesta inclui-se sua formação profissional21,22.

Para tanto, estes estudantes se colocam na condição alheia das outras pessoas, aprendendo a valorizar cada situação pessoal, a fim de estabelece rem melhor a relação médico-paciente em seu aprendizado profissional. Observa-se que os estudantes demonstram grande respeito à pessoa humana, aprofundando suas relações com o outro, ouvindo-o para tentar entender suas razões ${ }^{23}$.

A prendem a escutar seu paciente sem transferir expectativas e ansiedades, e esta escuta não significa necessariamente realizar o pedido que lhe está sendo feito, mas exercitam o compartilhamento da angústia de seu paciente na impossibilidade da realização de determinados pedidos, al iviando sofrimentos edividindo impotências, queédiferente de abandonar o paciente à própria sorte ${ }^{24}$.

0 mais importante desse primeiro contato com a população foi me colocar um pouco no lugar dos pacientes. $E$ isso ajuda-nos a entender como são as outras pessoas do nosso mundo e aprender com 0 paciente a se colocar no lugar dele. (E1M 1)

Os estudantes, na construção de suas posturas ética e profissional, dentro da UPP, optam por respeitar a dignidadehumana, não passando por cima de toda experiência de vida e formação de uma história pessoal, entendendo e compreendendo 0 outro sem impor seus valores, diferentemente do que fazem os profissionais que sozinhos decidem a "melhor" conduta a se tomar para o paciente, justificada em seu conhecimento científico ena sua autoridade moral ${ }^{23}$.

0 mais importante é chegar e conversar com 0 paciente, procurando ser ético, sabendo se colocar no lugar do outro. Em primeiro lugar, você esta precisando dele porque se ele não se dispuser a te ajudar, vocênão vai aprender. Eleestá fazendo um favor para 
gente enão a gente está fazendo um favor para ele. E sempre procurar respeitar o paciente, sua cultura. Porque às vezes é um choque de costumes e conhecimentos, tem que respeitar suas vontades. (E3M 1)

Confidencialidade da informação no desenvolvimento do sigilo profissional médico

Nesta categoria, os estudantes de medicina, notadamente os da 1a série, denotam uma atenção especial para o sigilo profissional. Há grande preocupação em manter a privacidade das informações referentes à história clínica de seus pacientes e em definir o momento em que as informações dos pacientese desuas famílias devem ser compartilhadas com a equipedesaúde, especialmentecom um agente comunitário, que évizinho daquele paciente.

Constroem em sua formação a preocupação com o princípio ético da privacidadeea necessidade da manutenção do sigilo profissional, que se destaca entre os direitos dos usuários na construção da humanização dos serviços de saúde, queéo direito à privacidade de suas informações. Este é um princípio derivado da autonomia, que engloba a intimidade, a vida privada, a honra das pessoas e significa o direito dos usuários decidirem 0 controle de suas informações pessoais e de como estas devam ser compartilhadas e utilizadas ${ }^{25,26}$.

Algo que me preocupa: é expormos as pessoas. Escrevemos a anamnese em prontuários e às vezes pessoas como agentes comunitários, que moram no mesmo bairro, têm acesso.E isto me deixa preocupado. (E1M 1)

Acredito que não seja ético fazer discussão acerca dos pacientes entre toda a equipe desaúde. Falar 0 que vimos na casa do outro. Não devemos expor isso para várias pessoas. Eu não gostaria que as pessoas fizessem isto da minha vida. (E10M 1)

Eu nunca falei para os pacientes quais destinos teriam suas informações, mas temos que ter responsabilidade sobreas informações, pois os pacientes têm o direito de saber qual o destino que vai ser dado a sua informação. (E3M 1)

Reconhecem, entretanto, conjuntamente com seusfacilitadores, queem muitas vezes háa necessidade de quebra deste sigilo perante profissionais médicos e enfermeiros da USF, a fim de eventual utilização destas informações em prol do próprio paciente, mostrando responsabilidade com as informações que lhes são fornecidas e prudência em suas atitudes.

Esta troca de informações entre os elementos da equipe de saúde é entendida como necessária, mas devendo ser limitada àquelas informações que cada profissional precisa para realizar suas ativi- dades em benefício para o cuidado do paciente ${ }^{25,26}$.

Q uando discutimos os casos dos pacientes juntos, acabamos elaborando um plano terapêutico juntos. E se estamos discutindo em grupo, surgem idéias que ajudam uns e os outros. (E4M 1)

Tem informações que não sei até que ponto você tem que contá-las ou não, se a gente vai estar traindo a confiança do paciente ou estar ajudando ele por contar ao médico. (E10M 2)

Demonstram, então, maturidade ao lidarem com informações dos pacientes, assim como atitudes profissionais condizentes com o que se espera defuturos profissionais médicosqueserão. Com isso, coloca-se em prática a pedagogia crítica, em que se incorpora a experiência do acadêmico ao currículo, e o entendimento e resolução das contradições sociais e éticas que se vive.

As relações interpessoais na formação ética do estudante de medicina

Osestudantes nesta categoria demonstram como constroem suas relações interpessoais com o outro. Estabelecem, para tanto, relações éticas pautadas em respeito às concepções dos pacientes, assim como ilustram o respeito à autonomia destes ao se envolverem, desde o início do curso, em seu cuidado.

Esta mesma autonomia é que traz ao sujeito a possibilidade de ser responsável por suas ações com responsabilidade, e consciência das consequências delas, pensar por si próprio, decidir por sua vida e ser responsável por ela, estabelecendo seu próprio código de ética, que, também, pode ser conduzido por códigos externos ${ }^{24}$.

No contexto da relação médico-paciente, o crité rio de autonomia é recente, colocando de lado o critério fundamental de beneficência que privilegia 0 médico como sujeito e coloca o paciente como objeto do cuidado (evitar o mal possível e promover o bem, favorecer a qualidade de vida). A autonomia trata como autônomos médico e paciente nas relações interpessoais, que compartilham decisões em parceria eem gozo de plenos direitos ${ }^{24}$, e os estudantes têm construído esta relação durante suas ações de saúde nas ações de saúde com a comunidade.

É claro que o princípio da beneficência é inseparável do da autonomia, mas neste momento ambas as partes são competentes e passam a fazer uma escol ha conscientee adequada ao paciente. Envolvem-se, então, nesta situação, mudanças dementalidade na equipe de saúde e instituições sobre o conceito de que o médico é o único depositário do saber, e da visão paternalista de que somente ele conheceo queébom para o paciente. N estesentido, os estudantes auxiliam a pessoa a exercer sua autonomia, auxiliando-a a buscar sua autonomia e a 
comunicar seus desejos, quebrando a visão paternalista mencionada ${ }^{24}$.

I sso faz parte da postura profissional que a gente está tendo, querendo ou não éuma postura profissional quea gente está tendo ali. Às vezes o paciente diz não pode nos atender. É, ele tem queter liberdade de te falar: "Vocês vão ter que vir outro dia! Porque nos não vamos dar atenção para vocês!" E daí a gente falou: "Tudo bem! Isso faz parte". (E1M 1)

A primeira preocupação éa de respeitar o espaço do outro porque, de certa forma, estamos invadindo o espaço de alguém. (E6M 1)

É muito importante deixarmos claro para eles sobre a realização do exame físico. Perguntar se a pessoa não se incomoda com isto. Tem que deixar claro para elesquea gente está aprendendo, eseela se importar, a gente não faz. (E2M 2)

Esta categoria resume a oportunidade que os estudantes têm de estar se relacionando com 0 outro na construção de seus saberes, colocando em exercício o respeito à cultura do outro.

Assim, os estudantes se relacionam diferentes da visão subjetiva e coletiva que congrega valores acerca do profissional médico advindos de uma representação histórica, remetida a Hipócrates de Cós, na qual há forte traço paternalista de que "0 médico sempre sabe o que há de melhor para o seu paciente". D elineia-se, então, um novo perfil médico na relação com o paciente, capaz de ser autônomo, julgar, tomar decisões e ter ações éticas ${ }^{20,27}$.

Nesta categoria, também se evidencia que o cenário da ABS possibilita ao estudante o vínculo e a responsabilidade com as famílias da área de abrangência pela qual são responsáveis. Elucidam, contudo, o estabel ecimento dos limites da relação com 0 usuário, já quea proximidade das relações entreeles passa a ser estreitada na amizade e afetividade, ultrapassando o cuidado clínico, e tendo a invasão dos aspectosíntimos da dinâmica familiar. Esta proximidade com as famílias levanta questionamentos quanto à interferência dos estudantes no estilo de vida das famílias ou usuários, assim como a interferência dos pacientes na vida dos estudantes ${ }^{28}$.

Tem uma paciente que a gente consegue conversar com ela no máximo uma hora. Ela começa a ficar impaciente. Então temos que ir embora. (E3M 2)

É uma relação detroca mútua. Temos queaprender a respeitar os limites dos pacientes, mas também temos que saber colocar nossos limites. Porque somos pessoas normais. (E4M 1 )

Você tem que saber colocar seus limites para 0 paciente e deixar bem claro pra ele o que você sabee 0 que você não sabe. Tem que saber respeitar os direitos e fazer os seus serem respeitados. (E7M 1)

$\mathrm{H}$ avia uma paciente que tinha muita liberdade com a nossa dupla. Só que percebemos que ela estava indo longedemaiscom esta liberdadea ponto dequerer nosso tel efone, fossemos na festa do filho dela. Então passamos a não falar da nossa vida pessoal para não comprometer nossas relações. (E2M 2)

\section{Consideraçõesfinais}

Evidenciam-se, então, percepções éticas comuns entre os estudantes das duas primeiras séries que desenvolvem atividades no cenário da ABS, notadamente a presença de fal as que representam uma formação ética diferenciada das que ocorrem em outras escolas médicas, que ainda formam profissionais que desconsideram as opiniões das pessoas enfermas.

0 ensino da ética nos cursos de medicina, ainda hoje, caracteriza-se quase que exclusivamente pela abordagem deontológica. Esse enfoque dos direitos e deveres profissionais gerou o modelo norte-americano de medicina defensiva, queameaça instalar-se entre nós. 0 caminho da ética passa a ser pavimentado por leis e os médicos, orientados por advogados ${ }^{29}$.

Há que se buscar novos modelos de ensino, pois a sociedade assim o pede. A rígida deontologia calcada nos antigos mandamentos hipocráticos encontra-seexaurida. A modernidadedesconstruiu o médico semideus e o quer humano, sensível e não mais um pai autoritário e despótico29.

Logo, a Famema, através da UPP, propõe formar médicos que tenham a preocupação com a promoção de qualidade de vida dos pacientes, 0 respeito à autonomia destes pacientes, a construção de posturas éticas adequadas em seu processo de ensino-aprendizagem; afinal, o estudante passa a vivenciar as relações do dia a dia com as quais conviverá futuramente em sua profissão.

Esta estratégia educacional mobiliza a construção de mudanças, notadamente ao se pretender atingir a reflexão crítica eética das relações em saúde, trazendo para a formação a capacidade de aprender a aprender, trabalhar em equipe, comunicar-se, relacionar-se com o outro econstruir uma prática ética e reflexiva nas relações com o outro.

Uma realidade se forma então, crítica e inovadora dos sujeitos, em que se pretende uma nova forma de estar e viver a formação médica, confrontando valores e explorando problemas e situações na construção de uma notável formação profissional ${ }^{29}$.

Portanto, é primordial a inserção em cenários de práticas, como o da Atenção Básica em Saúde, desde o início do curso médico, para se construir saberes condizentes com as reais necessidades de saúde da população. Tem-se, então, como desafio, 
incentivar novas experiências, como a da Fame ma, e a constante (re)construção da UPP, a fim de torná-la ainda mais responsável por processos de mudanças sociais, culturais e educacionais na formação dos profissionais médicos.

\section{Colaboradores}

RC Ferreira, RF Silva, Zanolli MB e CRR Varga participaram igualmente de todas as etapas da elaboração do artigo.

\section{Agradecimentos}

Agradecimento especial pelo apoio e incentivo à amiga Aline Redígolo Silva da Famema.

\section{Referências}

1. Alarcão I. Escola reflexiva e nova racionalidade. Porto Alegre: Artmed; 2001.

2. Piancastelli $\mathrm{CH}$. Saúde da família e formação de profissionais de saúde. In: Arruda BKG, organizador. A educação profissional em saúde e a realidade social. Recife: Instituto Materno Infantil de Pernambuco (IM IP); 2001. p.121-140.

3. Feuerwerker LCM. A construção de sujeitos no processo de mudança da formação dos profissionais de saúde. Divulg Saúde Debate 2000; 22:18-24.

4. Azevedo EES. Ensino de bioética: um desafio transdisciplinar. Interface (Botucatu) 1998; 2:127-137.

5. Feuerwerker LCM. Além do discurso de mudança na educação médica: processos e resultados. São Paulo: Hucitec; 2002.

6. Schramm FR. Contribuição da bioética e da comunicação à educação médica. Rev Bras Edu M éd 2001; 25(2):15-23.

7. Almeida JLT, Schramm FR. Transição paradigmática, metamorfose da ética médica e emergência da bioé tica. Cad Saúde Pública 1999; 15(Supl. 1):15-25.

8. Taquette SR, Rego S, Schramm FR, Soares LL, CarvaIho SV. Situações eticamente conflituosas vivenciadas por estudantes de medicina. Rev Bras Educ M éd 2005; 51(1):23-28.

9. Araújo RW. A ética do ensino médico e o ensino da ética médica. In: Assad JE, organizador. Desafios éticos. Brasília: Conselho Federal de M edicina; 1993. p. 88-92.

10. Rego SA. A formação ética dos médicos: saindo da adolescência com a vida (dos outros) nas mãos. Rio de Janeiro: Fiocruz; 2003.

11. Siqueira BP. A ética do estudante de medicina. In: Assad JE, organizador. Desafios éticos. Brasília: Conselho Federal de Medicina; 1993. p.93-96.

12. Glock RS, Goldim JR. Ética profissional é compromisso social. Porto Alegre: M undo Jovem; 2003.

13. Roque MV. A relação pessoal como acesso privilegiado para o doente mental grave. Bioética 2001; 9:53-62.

14. Ferreira RC, Silva RF, Aguer CB. Formação do profissional médico: a aprendizagem na atenção básica de saúde. Rev Bras Educ M éd 2007; 31(1):52-59.

15. Tyler RW. Princípios básicos de currículo e ensino. Porto Alegre: Globo; 1976.
16. Faculdade de Medicina de Marília. Avaliação da Unidade de Prática Profissional - 1o semestre de 2003: estudantes de enfermagem e medicina. M arília: Faculdade de Medicina de M arília; 2004.

17. Richardson RJ. Pesquisa social: métodos e técnicas. São Paulo: Atlas; 1999.

18. Tobar F, Yalour M R. Como fazer teses em saúde pública: conselhos e idéias para formular projetos e redigir teses $\mathrm{e}$ informes de pesquisa. Rio de Janeiro: Fiocruz; 2001.

19. Bardin L. Análise de conteúdo. Lisboa: Persona; 1996.

20. Turiel $\mathrm{E}$. The development of concepts of social structure: social convention. In: Glick J, Larke-Stewart A, editors. The development of social understanding. $\mathrm{New}$ York: Gardner Press; 1978. p. 25-108.

21. Costa CRBSF, Siqueira-Batista R. As teorias do desenvolvimento moral e o ensino médico: uma reflexão pedagógica centrada na autonomia do educando. Rev Bras Educ M éd 2004; 28(3):242-250.

22. Piaget J. A equilibração das estruturas cognitivas. Rio de Janeiro: Zahar; 1976.

23. Freitas IRS. A bioética nas relações interpessoais. In: Siqueira JE, Prota L, Zancanaro L, organizadores. Bioé tica: estudos e reflexões. Londrina: UEL; 2000. p. 167-184.

24. Miranda JM. Tecnociência, autonomia e dignidade humana na área da saúde. In: Siqueira JE, Prota L, Zancanaro L, organizadores. Bioética: estudos e reflexões. Londrina: UEL; 2000. p. 101-116.

25. Fortes PAC, Spinetti SR. O agente comunitário de saúde e a privacidade das informações dos usuários. Cad Saude Publica 2004; 20(5):1328-1333.

26. Sacardo DP, Fortes PAC. Desafios para a preservação da privacidade no contexto da saúde. Bioética 2000; 8:307-322.

27. Siqueira-Batista R. Deuses e homens. Mito, filosofia e medicina na Grécia antiga. São Paulo: Landy; 2003.

28. Zoboli ELCP, Fortes PAX. Bioética e atenção básica: um perfil dos problemas éticos vividos por enfermeiro e médicos do Programa Saúde da Família. Cad Saude Publica 2004; 20(6):1690-1699.

29. Eisele RL. $O$ ensino da ética no curso de Medicina. In: Siqueira JE, Prota L, Zancanaro L, organizadores. Bioé tica: estudos e reflexões. Londrina: UEL; 2000. p. 221-229.

Artigo apresentado em 30/10/2006

Aprovado em 22/08/2007

Versão final apresentada em 18/10/2007 